\title{
DESNUDEZ EN TRES ACTOS
}

Diego Álvarez ${ }^{1}$

\section{Resumen}

E ste artículo es un intento por presentar una perspectiva distinta de reflexión en torno a los problemas sobre derechos y ciudadanía que se ven desbordados en su mera comprensión teórica, cuando son mirados a la luz de tres actos, tres situaciones tristemente cotidianas en nuestro país y respecto a las cuales se revela como común denominador la desnudez de la existencia humana, la vida desnuda, que con vehemencia pone en cuestión la validez fáctica de unos discursos que no son suficientes para dar sentido a una realidad que desborda toda racionalidad posible. En virtud de esto se revela lo que diferentes autores han expresado como unas profundas crisis de los conceptos de derechos, libertades, ciudadanía y consecuentemente, de democracia.

\section{Palabras Claves}

Desnudez humana, corporalidad, derechos, ciudadanía.

\section{Abstract}

This paper is attempts to present a different approach on the problems rights and citizenship that are overflowed in their theoretical understanding, when they are watched in the light of three acts, three sadly daily situations in our country and with respect to which reveals like common denominator the nakedness of the human existence, the naked life, that with vehemence puts the factual validity of speeches at issue that are not sufficient to give sense to a reality that overflows all possible rationality. By virtue of this it is revealed what different authors have expressed like a deep crisis of the concepts of rights, liberties, citizenship and consequently, of democracy.

\section{Keywords}

Human nakedness, corporality, rights, citizenship.

Recibido el 10 de julio de 2010, aprobado el 26 de agosto de 2010

\section{Primer acto}

Frente a una cámara, se nota casera, aparece un hombre de tez morena, quien tiene una de sus extremidades superiores amputadas -alguna vez llegué a pensar que lo que planteaban Deleuze y Guattari en su Texto de Mil Mesetas, acerca de la necesidad que tiene el aparato de Estado de tarados previos, mutilados y preexistentes, era tan sólo una metáfora-(Deleuze y Guattari, 2006, p. 435), otro,

1. Magíster en Investigación Social Interdisciplinaria de la Universidad Distrital Francisco José de Caldas y perteneciente a la Línea de Poder, Política y Nuevos Sujetos Sociales de la misma. 
a su lado derecho, con una macheta en la mano le exige a quien ya se encuentra amputado que coloque el huesito sobre la piedra y que si no lo hace, se la pone -la macheta- en la cabeza. El hombre, que va a perder la única mano que le queda, con voz entrecortada, con dejo de imploración y de impotencia infinitas le pide, no que no se la ampute si no que le de permiso de salir corriendo una vez lo haya hecho. Se arrodilla, pone la mano sobre la piedra -en este momento, y llámenme cobarde o díganme que me faltan agallas para alimentar mi morbo, pero sólo puedo minimizar la ventana del computador en la que se está reproduciendo este videose escucha el chin de la macheta golpeando contra la piedra, un quejido con desgano del campesino al que ahora le faltan ambas manos y la escena finaliza con una carcajada, supondría yo del camarógrafo o de quienes presencian esta amputación.

\section{Segundo acto ${ }^{2}$}

Un joven que trabaja como ayudante de construcción en el municipio de Soacha, le informa a su mamá, Doña Blanca, que hoy (2 de marzo de 2008) no se dirige a la obra, sino que tiene una cita con una persona que le va proponer un nuevo trabajo y que vuelve a tiempo para la cena. El puesto del joven no es ocupado esa noche, ni las cinco siguientes, razón por la cual su madre pone la denuncia de su desaparición. Dona Blanca sólo se enterará de la muerte de su hijo seis meses después de ocurrida, cuando el cuerpo del joven sea hallado en una fosa común en Ocaña, Norte De Santander (El Tiempo, 2008, 4 de noviembre); en un primer momento es reportado como baja propinada por el ejército a la guerrilla. Lo más probable es que este cuerpo sin vida, junto a la docena de otros cuerpos encontrados en el área, todos provenientes de Soacha, llevara puesta una sudadera debajo del camuflado y que no llevara puestas medias, a pesar de calzar botas de caucho. Todo esto en el escenario del Catatumbo, en donde las temperaturas rondan los $35^{\circ}$ centígrados (El Tiempo, 2008, 15 de octubre).

\section{Tercer acto}

Un hombre de 46 años de edad, propietario de una finca en las estribaciones de la Serranía de la Macarena, se niega a darle gasolina a unos guerrilleros de las FARC; días después, mientras se encontraba bañándose en el río, éstos lo secuestran por no haber colaborado con la causa revolucionaria. Nunca se dieron pruebas de supervivencia de don Sandalio, ni se exigió suma alguna de dinero por su liberación. Por tal razón, la familia de éste secuestrado decidió hacer el duelo y declararlo como muerto seis años después de su secuestro, ocurrido en 1981. Sin embargo, hace año y medio una mujer les dio información y detalles inconfundibles de don Sandalio que hacen pensar que éste aún se encuentra con vida. Ha pasado por varios frentes, por varios comandantes, más ni siquiera uno de ellos sabe a ciencia cierta el por qué una persona permanece 26 años secuestrada, y afirma que los jefes guerrilleros muchas veces no saben las razones y tan sólo cumplen con ir con los secuestrados de un lado para otro (El Tiempo, 2009, 7 de enero).

Cualquier persona podría pensar que las anteriores descripciones simplemente hacen parte de las escenas que a diario se viven en el marco del conflicto armado colombiano, y que bastaría con clasificar a la primera como una acción perpetrada por los paramilitares, la segunda como llevada a cabo por las fuerzas armadas, y la última, como un accionar de la guerrilla de las FARC. Pero hay más:, existen elementos compartidos por estas acciones que nos pueden llevar a un análisis de la forma como actualmente están siendo entendidas, sometidas y desaparecidas las personas. Para tal análisis, poco vale que nos sometamos a lecturas trilladas tales como que son personas a las que les están siendo vulnerados sus derechos, que estas son claras violaciones del D.I.H, o que ésta es la imagen de la degradación del conflicto colombiano. No; lo que comparten éstas escenas es una desnudez, es de ésta y no de derechos de la que queremos hoy hablar. 


\section{¿Por qué hablar de desnudez y no de derechos?}

En primer lugar, por no seguir el juego a la idea que la democracia liberal ha pregonado desde hace más de dos siglos, de que todos somos iguales porque tenemos derechos. ${ }^{3}$ Ésta idea ha logrado permear las más variadas constituciones a lo largo y ancho del planeta, incluso la nuestra, ${ }^{4}$ y ha naturalizado la libertad como algo emanado a través de un texto jurídico. Con relación a las escenas presentadas en este artículo, no podríamos dejar de preguntarnos: ¿El personaje del primer acto tuvo la libertad de escapar de la mutilación por el simple hecho de que diversos textos garantizaran su libertad, su vida, el no sometimiento a torturas, la paz, la dignidad, la posesión de bienes y la pluralidad de creencias? ¿Pudo gozar de su libertad y derechos el joven de Soacha aún cuando la institución que debería garantizarselos fue quien se los negó? ¿Corrió distinta suerte don Sandalio?

En toda esta tradición liberal está presente una interpretación negativa de la libertad. Se la entiende como algo que es dado de antemano a través de una declaración o una constitución, como una garantía respaldada por unos derechos, que son tales por la simple razón de estar escritos en documentos legitimadores de soberanías, Estados y humanidades. ¡Cuán pronto se olvida que los derechos son una conquista, pero no de unos pelucones en una revolución de otras latitudes y otros siglos!. Ellos obtuvieron sus derechos por conquista, no por texto. Pero en las condiciones actuales, con frecuencia se entiende a los sujetos en un contexto medieval, como sujetos de derechos. Si los derechos son una conquista, la libertad no puede ser otra cosa más que una práctica. Es en la medida en que los sujetos ejercen su libertad, practican la libertad, que ésta se hace manifiesta, no en las letras que acompañan preámbulos y artículos. De otra forma, podemos seguir hablando de los derechos como la cosa más violada en la historia del mundo.

A los sujetos que padecieron los efectos de una dominación severa en los tres actos aquí descritos no les fue violado ningún derecho; éstos simplemente no han existido para ellos, toda vez que sus condiciones históricas, culturales y materiales les han impedido ejercer su libertad, llevarla a cabo como una acción, y les han obligado a padecerla como letra muerta en una constitución. Por tal motivo, sus derechos no fueron violados; simplemente están desnudos.

\section{Desnudez y ciudadanía}

Para ellos no aplica el concepto de ciudadanía; más aún, en ellos se revela con profundidad la abstracción moderna que quiso vincular la soberanía de los Estados Nacionales al pueblo devenido sujeto colectivo ciudadano. En las condiciones actuales, es la vida misma la que se pone en juego en la apuesta política, una apuesta que ya no admite abstracciones modernas como pueblo, contrato social o incluso ciudadano, pues el biopoder no controla configurando sujetos sino "biologicidades". Como lo señala Foucault, lo que hoy está en juego en juego es la vida, y es por ello que la política se ha convertido en biopolítica (Agamben, 1997, p. 16).

Esta no actúa, como podría llegar a pensarse, sobre individuos encerrados, o más bien, sobre cuerpos individuales, en lo que Foucault ha llamado una anatomopolítica, que correspondería a una sociedad disciplinar y a sus espacios de encierro. Lo que observamos es un biopoder que opera sobre poblaciones enteras, ya sea desplazándolas, condenándolas al hambre, asesinándolas o integrándolas en programas de ayuda o de cooperación. Ya no hay distinción: de lo que se trata es de controlar poblaciones y no sólo docilizar individuos con miras a hacerlos más productivos. Poblaciones que pueden ser desplazadas de un modelo económico en la ciudad o que son desplazadas por la violencia, que ingresan a la urbe y (en el mejor de los casos) son cooptadas - atendidas por programas de ayuda dirigidos a las familias más desprotegidas o desplazadas. Tan pronto como son atendidas, beneficiadas o incluidas en programas de atención, por este mismo hecho son excluidas de ejercicios y dinámicas decididamente ciudadanas, aún cuando discursos insensatos insisten en vincular

3. Los hombres han nacido, y continúan siendo, libres e iguales en cuanto a sus derechos. Extracto del primer artículo de la Declaración Universal de los Derechos del hombre y del Ciudadano.

4. Ver el Preámbulo y los dos primeros artículos de la Constitución Política de Colombia de 1991. 
la ciudadanía allí donde no es posible establecer vinculo alguno con los derechos. Es por ello que se habla sin mayor cuestionamiento de ciudadano habitante de la calle o de ciudadano desplazado.

Hoy es necesario hablar de desnudez y no de ciudadanía; es preciso decir que en la actualidad no hay traje político alguno que logre cubrir a las poblaciones retratadas en las tres escenas con las cuales inicia el presente artículo. ¿Podríamos hablar acaso que ejercen la ciudadanía las poblaciones campesinas, desplazadas, torturadas, mutiladas? ¿Acaso la ejercen los jóvenes que encuentran la muerte como última gestión de un Estado que se empeña en mostrar resultados en seguridad democrática a través de su población más vulnerable? En últimas, ¿lo hacen quienes se encuentran cautivos en las montañas de Colombia?

En este escenario se presenta ante nosotros la tarea inaplazable de llevar hasta sus últimas consecuencias la obsolescencia de los Derechos del Hombre y el ocaso del Estado Nación (Agamben, 1997, p. 24); y con ella, una postura que no reconozca límites estatales (cada vez más borrosos), ni derechos hechos para cualquier otra subjetividad, menos para seres humanos. Este hecho queda resaltado cuando vemos, como lo señala Hannah Arendt, que el refugiado, aquel que ha perdido toda cualidad y relación específicas menos el hecho de ser humano, es a quien primero le son negados lo Derechos del Hombre, base fundamental y elemento constitutivo de cualquier ciudadanía (Agamben, 1997, p. 24). Es decir, que aquel que soportaría menor cantidad de abstracciones, el sujeto que demandaría sin demora alguna la aplicación y ejercicio íntegros de los Derechos del Hombre, es a quien primero se le han negado. Pareciera, en últimas, que en cuestión de derechos, occidente le ha negado este ejercicio a quienes más los necesitan. En nuestro caso, hablaríamos de desplazados, desaparecidos o secuestrados, los cuales emulan fielmente la figura que Arendt tiene en mente cuando habla de refugiados.

\section{¿A quién le conviene la desnudez?}

Es preciso aclarar que, según señalábamos al iniciar el artículo, no estamos hablando aquí de víctimas del conflicto armado. En este punto nos alejamos de las tesis que plantean que el desplazamiento es generado por la guerra, las desapariciones forzadas por el afán de mostrar resultados, o que los secuestros son usados como medio de financiación de la guerrilla para su proyecto de guerra. El desplazamiento, con todo el horror y la violencia ejercida sobre los cuerpos, es una disputa por el territorio, aquel que quiere ser cooptado por el mercado capitalista y que encuentra en la desmembración una proyección del fin del vínculo del campesino con su tierra. Vinculados a este ejercicio de despojo se encuentran los demás actores armados que se deleitan en la desnudez de las poblaciones pues, en últimas, el ejército no le reconoce ciudadanía alguna a las personas denominadas por ellos como "falsos positivos", y mucho menos lo hace la insurgencia en el caso de los secuestrados.

Por lo tanto, estamos hablando de un operar que nos muestra un engranaje de estructuras políticas, armadas y económicas, que trabajan fundamentalmente en función de ésta última, y en donde ya no se precisa saber, con el fin de entender, si se trata de estructuras lícitas o ilícitas; todas han sido teñidas por el mercado y su monetarismo. Así mismo, en su conjunto, no apuntan ya a individuos, sino a poblaciones; es su gestión lo que se busca, y ésta gestión tiene varios niveles, tales como la asistencia, el desplazamiento, el confinamiento o la misma muerte.

En este sentido en necesario recordar que la seguridad, entendida como un dispositivo, se ejerce sobre la población en su conjunto (Foucault, 2006. p. 27), ya no sobre individuos puntualmente producidos en espacios de encierro, sino sobre colectividades y las relaciones que las mismas establecen con la economía en términos de costos: el costo de su represión y el costo de su delincuencia. Ya no más sujetos de derechos; tan sólo poblaciones privadas de ellos, y ¿con qué argumentos?, en nuestro caso es familiar: seguridad democrática, seguridad regional, aseguramiento interno, etc. El miedo como campo de intervención, donde se busca afectar a una población (Foucault, 2006, p. 41); el miedo y el pánico como los grandes argumentos de la política moderna. El atentado y el accidente, mejor aún, el atentado presentado como accidente y viceversa, que busca lograr 
lo que antaño se conseguía por medio de guerras y revoluciones. Así, no estaríamos ante una confrontación -vista desde la perspectiva marxista- entre los poseedores de los medios de producción y los desposeídos de los mismos. Lo que hoy se incorpora en una desposesión de los medios mismos de producción de la vida. En este sentido, bien podemos observar todo aquello que viene pasando con el agua y quienes la reivindican como derecho frente a quienes la entienden como servicio, o la usurpación de tierras a indígenas que en muchos casos tienen un vínculo sagrado con ella. Por lo tanto, no hablaríamos de individuos despojados de sus medios de producción, sino de poblaciones que están siendo gestionadas en el medio mismo que les posibilitaría la vida. ${ }^{5}$

La conveniencia de la desnudez es, pues, fundamentalmente económica; reporta beneficios y se entiende en términos centrífugos, como incorporar nuevos elementos e integrar al mercado mundial territorios. Pero antes de ello hay que convertir estos territorios en algo productivo. La producción de territorios con vocación a integrarse en dinámicas globales depende en gran parte de la posibilidad de producir a sus residentes como productores; en caso de no poder hacerlo, éstos simplemente son desplazados o asesinados. Pensemos en el caso de los desplazamientos ocurridos en nuestro territorio con relación al cultivo de palma aceitera, fundamentalmente en la costa del pacífico. Aquellos pocos que tendrían la posibilidad de quedarse allí, sólo lo harían con la condición de modificar sustancialmente su relación con la tierra, y así pasarían de campesinos a empleados agrícolas.

No es simple coincidencia que las zonas del país con mayores índices de desplazamiento sean precisamente aquellas donde se haya concentrada la riqueza; es decir, los desplazamientos no sólo han ocurrido en zonas importantes a nivel militar como corredores, zonas de repliegue y presencia tradicional de actores armados, sino que también se han concentrado principalmente en zonas con recursos estratégicos y dinámicas económicas importantes (Fajardo, 2002). En este contexto estaríamos hablando que no es el conflicto armado el que produce la desnudez de las poblaciones en
Colombia, sino que se desnuda (se desplaza, se tortura, se desaparece, se invisibiliza, etc.) a éstas, fundamentalmente con el fin de despojarlas de sus territorios, de romper el vínculo que las une a ellos e interconectarlos con lógicas y mercados globales.

Así, la desnudez se presenta en este escenario como la condición extrema de desarraigo y de no pertenencia a ningún territorio, ni siquiera al del propio cuerpo, pues en muchas de las ocasiones en que las poblaciones son desnudadas, al perder su traje político, sus miembros más vulnerables sufren la pérdida de soberanía sobre su cuerpo. Estas personas nos recuerdan así que, históricamente, la conquista territorial y la violación de los cuerpos han ido de la mano (Segato, 2008, p. 77), más aún aún en el caso colombiano, en el que estos episodios no han sido suficientemente revelados, cuestionados ni mucho menos reparados en los recientes procesos de desmovilización de grupos armados.

\section{Consideraciones finales sobre la complacencia que produce la desnudez}

Estaría por demás señalar la fascinación que en la actualidad produce la exposición del cuerpo y el énfasis en la genitalidad. LSe trata dea pornografía, entendida no como un juicio moral con relación a la mirada que se tiene del cuerpo, sino más bien en el sentido señalado por Baudrillard, como aquel exceso de imágenes que acuden ante nosotros, al igual que el primer plano sexual en el porno (Baudrillard, 1997, p. 16).

Estas transparencias ya no sugieren; tan sólo exponen. ¿Cuál es la cercanía entre un seno, una nalga o las poblaciones aquí descritas? La exposición, la desnudez, aquello que ya no se oculta para las poblaciones, son puras biologicidades -nos recuerda Foucault. Es aquello que ya no se oculta en las pantallas: una obscenidad que acaba con toda mirada imagen o representación, lo que Baudrillard va a llamar "pornografía de la información y la comunicación"(Baudrillard, 1997, p. 17).

Tal vez no sea descabellado afirmar que la fascinación por los cuerpos desnudos, tan sólo 
sea una consecuencia lógica de la fascinación por la desnudez de las poblaciones. El pueblo ya no sugiere derechos, se muestra en su desnudez, muestra su realidad más allá de toda ficción moderna, no lo cubre ningún traje, ninguna mediación. Los desnudos son imágenes en las cuales ya no hay nada que ver (Baudrillard, 1997, p. 26). ¿Que buscamos al acercarnos a un desnudo? ¿Acaso un pelo? ¿Un poro? Cuando un espectador se acerca a un desnudo, probablemente no lo hace por curiosidad sexual, sino para comprobar "la textura de la piel, la textura infinita de lo real"(Baudrillard, 1997, p. 26). Con Baudrillard podríamos decir entonces que la desnudez sólo sirve como intento desesperado para subrayar la existencia de algo (Baudrillard, 1997, p. 26) y que, aún desnudadas, las poblaciones son un acontecimiento que mueve las bases de la comprensión política del presente. ¿Que traje han llevado desde el momento en que se plantean como objeto de la gobernabilidad? No muy lejos, se oye la voz de Hans Christian Andersen, quien nos dice: miren el traje nuevo del emperador, lo han robado, las poblaciones han sido cubiertas con este.

\section{0}

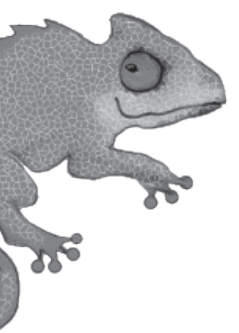

\section{Fuentes bibliográficas}

Agamben, G. (1997). Medios sin fin. Valencia: Pre-textos.

Baudrillard, J. (1997). El Otro por sí mismo. Barcelona: Editorial Anagrama.

Deleuze, G. y Guattari, F. (2006). Mil Mesetas. Valencia: Editorial Pretextos.

Fajardo, D. (2002). Para sembrar la paz hay que aflojar la tierra. Bogotá: Universidad Nacional de Colombia.

Foucault, M. (2006). Seguridad, territorio, población. Argentina: Fondo de cultura económica.

Segato, R. L. (2008). “En busca de un léxico para teorizar la experiencia territorial contemporánea". En (Des) territorialidades y (No) lugares: procesos de configuración y transformación social del espacio. Medellín: Ediciones la Carreta. 